\title{
Risk Factors for Oral Human Papillomavirus Infection in Healthy Individuals: A Systematic Review and Meta-Analysis
}

\author{
Hideo Shigeishi ${ }^{\mathrm{a}, \mathrm{c}}$, Masaru Sugiyama ${ }^{\mathrm{b}}$
}

\begin{abstract}
Background: Oral human papillomavirus (HPV) infection is associated with oral cancer development. However, few epidemiologic investigations have focused on oral HPV prevalence in healthy individuals. The objective of this study was to provide updated information regarding oral HPV prevalence in patients without oral cancer worldwide.
\end{abstract}

Methods: We systematically reviewed 29 studies reporting the prevalence of oral HPV infection that included 22,756 subjects $(10,124$ males, 12,623 females, and nine unknown gender; age range 2 - 89 years) and were published from January 2012 to June 2015.

Results: The prevalence of overall HPV, low-risk type HPV, high-risk type HPV, and HPV16 in the reported cases was 5.5\%, 2.2\%, 2.7\%, and $1.0 \%$, respectively. The prevalence of overall HPV was considerably higher in males who had sex with males $(12.2 \%)$ as compared to heterosexual males $(4.7 \%)$ and females $(2.9 \%)$. A meta-analysis was performed to elucidate significant risk factors for oral HPV infection, which revealed a significant statistical association for oral sex and smoking with oral HPV infection (odds ratio (OR): 1.90, 95\% confidence interval (CI): 1.51 - 2.39, P $<0.0001$; OR: $2.13,95 \%$ CI: 1.32 - 3.43, $\mathrm{P}=0.002$ ).

Conclusions: Our findings suggest that sexual behavior and smoking are importantly related to oral HPV infection in healthy individuals.

Keywords: HPV; Infection; Risk factors; Meta-analysis

\section{Introduction}

The human papillomavirus (HPV) consists of a circle of

Manuscript accepted for publication March 31, 2016

aDepartment of Oral and Maxillofacial Surgery, Institute of Biomedical and Health Sciences, Hiroshima University, 1-2-3 Kasumi, Minami-ku, Hiroshima 734-8553, Japan

${ }^{b}$ Department of Public Oral Health, Institute of Biomedical and Health Sciences, Hiroshima University, 1-2-3 Kasumi, Minami-ku, Hiroshima 734-8553, Japan

${ }^{\mathrm{c}}$ Corresponding Author: Hideo Shigeishi, Department of Oral and Maxillofacial Surgery, Division of Cervico-Gnathostomatology, Graduate School of Biomedical Sciences, Hiroshima University, 1-2-3 Kasumi, Minami-ku, Hiroshima 734-8553, Japan. Email: shige@hiroshima-u.ac.jp

doi: http://dx.doi.org/10.14740/jocmr2545w double-stranded DNA (approximately 8,000 base pairs long) enclosed in an approximately $50-\mathrm{nm}$ protein capsid without an envelope and belongs to the family of papillomaviridae, with infection generally occurring in skin and mucosa $[1$, 2]. The HPV genome is composed of six early open reading frames (ORFs) (E1, E2, E4, E5, E6, and E7), two late ORFs (L1 and L2), and a non-coding long control region (LCR) [1]. The LCR sequence is important for regulation of viral replication and transcription of early genes. In the early 1980s, HPV16 was identified as the cause of cervical cancer by zur Hausen and colleagues [3]. To date, more than 150 HPV genotypes have been reported, of which approximately 40 infect the anogenital and oral mucosa regions [4]. Mucosal HPV types, associated with cervical, vulvar, vaginal, and anal cancers, are divided into low-risk and high-risk types [5].

HPV infection is a major cause of anogenital cancer, while oral HPV infection is also related to the development of oral cancer and prognosis of affected patients $[5,6]$. In addition, we previously reported that approximately $80 \%$ of HPV $16-$ positive oral epithelial dysplasia lesions finally progress to cancer [5]. These findings indicate that oral HPV infection is significantly associated with the malignant transformation of precursor lesions. Another study found that oral and oropharyngeal squamous cell carcinoma (OSCC) patients with an intra-tumoral HPV16 infection had better prognosis as compared to those without an HPV16 infection [6], indicating that HPV16 infection status may have prognostic significance in such cases. However, few epidemiologic studies have focused on oral HPV prevalence in healthy individuals (i.e., cancer free) and risk factors for oral HPV infection have not been fully elucidated. The objective of this study was to provide updated information about oral HPV prevalence in individuals worldwide without oral cancer. In addition, we performed a meta-analysis to find significant risk factors related to oral HPV infection.

\section{Materials and Methods}

\section{Search strategy}

The "PubMed" search engine of the National Institutes of Health was employed to search for the keywords "HPV" and "Oral" in studies published in English from January 2012 to June 2015, resulting in 640 papers found. After reviewing the titles and abstracts for relevance, we excluded reviews and 
meta-analyses $(\mathrm{n}=121)$, case reports $(\mathrm{n}=5)$, and in vitro analyses that used cell cultures or animal models $(n=91)$. We also excluded articles that focused on cases of oropharyngeal cancer, pre-malignant lesions, or inflammatory oral lesions $(\mathrm{n}=270), \mathrm{HIV}$-infected or immunosuppressed subjects $(\mathrm{n}=$ 28), subjects who had not been tested for oral HPV infection (i.e., those who underwent serological or cervical smear testing) $(\mathrm{n}=57)$, and subjects vaccinated against HPV $(\mathrm{n}=$ 17), as well as questionnaire surveys, brief communications, and commentaries $(n=6)$. That resulted in 45 eligible studies of oral HPV infection. Next, we excluded those that examined fewer than 100 subjects $(n=8)$ or infants $(n=2)$. As for studies focused on HIV-infected individuals, if HIV-negative subjects were included as controls, then that study $(n=6)$ was included in our analysis. We finally identified 29 papers after excluding those with overlapping study populations $(n=12)$ [7-35]. The data extracted were first author, publication year, country, year of study, study population, sample size, age, gender, sampling method, and HPV DNA detection method, as well as prevalence of any type of HPV, and high- and lowrisk HPV.

\section{Statistical analysis}

HPV prevalence was calculated by dividing the number of HPV-positive cases by the total number of cases tested. In addition, HPV type-specific contribution was defined by dividing the number of cases positive for a specific type (e.g., high- and low-risk HPV, and HPV16) by the total number of cases examined for a specific type. The odds ratio (OR) and $95 \%$ confidence interval $(\mathrm{CI})$ were calculated to examine risk factors for oral HPV prevalence. Overall heterogeneity across the analyzed studies was evaluated using the $\mathrm{I}^{2}$ statistic as the percentage of variation due to heterogeneity $\left(\mathrm{I}^{2}>50 \%\right.$ considered to be statistically significant). To summarize the ORs, a fixed-effect model (Mantel-Haenszel method) was used if no significant heterogeneity was present. When significant heterogeneity was present, a random-effect model (DerSimonian and Laird method) was alternatively applied. Publication bias was assessed using a funnel plot and Begg's rank correlation test. Data were analyzed using the statistical software EZR, which is a graphical user interface for R [36]. All statistical test results were considered significant at the level of $\mathrm{P}<0.05$.

\section{Results}

\section{Collection of oral samples}

We identified 29 studies that included 22,756 subjects $(10,124$ males, 12,623 females, and nine unknown gender; age range 2 - 89 years). They were conducted in the United States $(\mathrm{n}=$ $7)$, Brazil $(n=4)$, Australia $(n=2)$, Finland $(n=2)$, Sweden $(\mathrm{n}=2)$, Austria, Canada, China, Costa Rica, Germany, Hungary, Iran, Netherlands, Pakistan, United Kingdom, and South Africa $(n=1)$, and as a consortium of three countries (Bra- zil, Mexico, and United States) $(\mathrm{n}=1)$. Data for the selected variables (i.e., first author, publication year, country, study population, number of subjects, gender, age, sample collection method, HPV detection method, and HPV genotyping method) are summarized in Supplementary 1 (www.jocmr.org). As for the method of oral sample collection, oral swab, oral rinse, and saliva collections were conducted, with 15 studies $(51.7 \%)$ using oral rinse samples, $11(38.0 \%)$ using oral swab samples, and two $(6.9 \%)$ using saliva samples, while one $(3.4 \%)$ used both oral rinse and oral swab samples. In 11 of the 15 studies that used oral rinse samples, both oral rinse and gargle samples were collected, with Scope mouthwash (Procter \& Gamble) or saline utilized for those, though Scope mouthwash was more frequently employed.

\section{HPV detection and genotyping method}

As for the HPV detection method, consensus PCR targeting the HPV L1 region was commonly performed in 20 studies while direct HPV genotyping without HPV detection was performed in nine. The consensus PCR primers used in those 20 studies were PGMY09/PGMY11 $(\mathrm{n}=6)$, GP5+/GP6+ $(\mathrm{n}=$ 2), and MY09/MY11 ( $=1)$, while nested PCR using GP5+/ GP6+ and MY09/ MY11 primers was done in seven, and other primers were used in four. PGMY09/PGMY11 was the most commonly used primer set for HPV detection. For HPV genotyping, HPV genotypes were determined by hybridization of amplified HPV DNA with type-specific probes, restriction fragment length polymorphism (RFLP) analysis, or sequencing.

PCR was frequently employed for HPV detection with multiple consensus primers against L1, a highly homologous region in the HPV gene. Of the consensus primers, the PGMY09/PGMY11 set of primers is known to be more sensitive than MY09/MY11 and GP5+/GP6+, allowing for detection of more HPV types [37, 38]. PCR detection results reported in 20 studies showed a relatively wide variation $(0.67-34 \%)$ in the rate of HPV-positive cases, suggesting influence by the detection method as well as the subjects. For HPV genotyping, DNA hybridization with genotype-specific probes was frequently employed, as it is useful for detection of combined HPV infection, though less sensitive [39]. In addition, the cut-off values used are critical for this method, thus positive rates may vary with different values.

Based on previously reported epidemiological and biological data, 12 HPV types (HPV16, 18, 31, 33, 35, 39, 45, 51, 52, 56,58 , and 59) have been defined as group 1 human carcinogens according to the International Agency for Research on Cancer (IARC) [40, 41]. In addition, HPV-26, 53, 66, 73, and 82 have been defined as possibly carcinogenic (group 2B). In 29 of the present studies analyzed, patients possessing HPV16, $18,31,33,35,39,45,51,52,56,58,59,68$, and 73 were defined as high-risk type HPV (carcinogenic HPV), while those possessing HPV6, 11, 40, 42, 43, 44, 54, 55, 61, 62, 64, 67, 69, $70,71,72,81,83,84$, and 89 were defined as low-risk type HPV (non-carcinogenic HPV). HPV26, 53, 66, and 82 were defined as high-risk type HPV in three studies and low-risk 
A

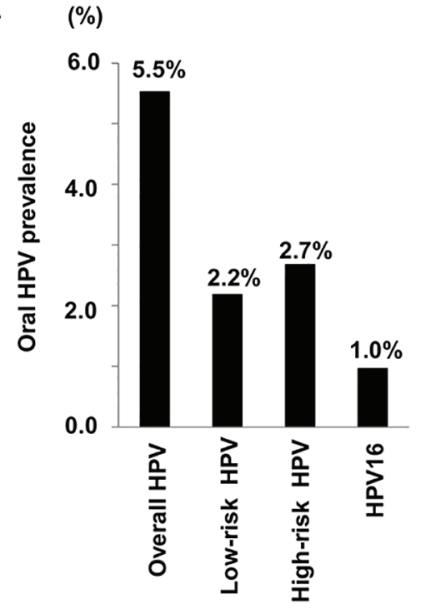

B

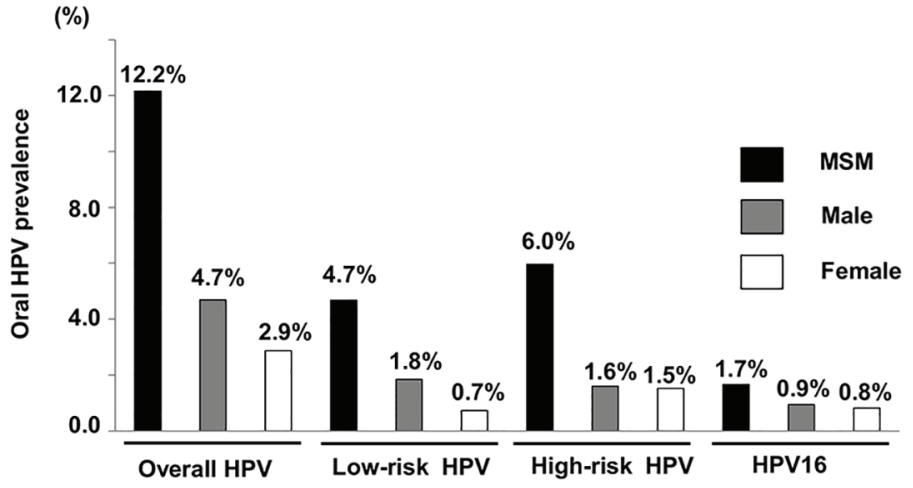

Figure 1. HPV prevalence of MSM, male and female. (A) Mean prevalence of overall HPV, low-risk type HPV, high-risk type HPV and HPV16. The prevalence rates for overall HPV, low- and high-risk type HPV, and HPV16 were 5.5\%, 2.2\%, 2.7\%, and 1.0\%, respectively. (B) Mean prevalence of selected oral HPV groups and HPV16 among MSM, male and female. The prevalence of all HPV types was considerably higher in the MSM group as compared to males and females.

type in four.

\section{Oral HPV prevalence in men who have sex with men, males, and females}

The mean values for oral HPV prevalence are shown in Figure $1 \mathrm{~A}$. The prevalence rates for overall HPV, low- and highrisk type HPV, and HPV16 were 5.5\%, 2.2\%, 2.7\%, and 1.0\%, respectively. The values for mean prevalence of HPV among men who have sex with men (MSM), males, and females are shown in Figure 1B. The prevalence of all HPV types was considerably higher in the MSM group as compared to males and females. In addition, the prevalence of overall and low-risk type HPV was higher in males than in females, whereas no significant difference was found for the prevalence of high-risk type and HPV16.

\section{Risk factors for oral HPV infection}

Several studies have found that sexual behavior (i.e., marital status, number of sex partners, oral sex, and anal sex), smoking, and alcohol drinking are significant risk factors for oral HPV infection [10-13, 20, 23, 30, 31, 33]. Therefore, we performed a meta-analysis to investigate the association between overall oral HPV infection and outcome, as described above. With regard to sexual behavior, the prevalence of oral HPV infection was increased in subjects who had experience with oral sex as compared to those who did not, and a significant statistical association was found between oral sex and oral HPV infection (OR: 1.90, 95\% CI: $1.51-2.39, \mathrm{P}<0.0001$ ) (Fig. 2A). Furthermore, we performed a meta-analysis to examine the association between oral sex and HPV infection in females $[12,18,20,23]$, though no statistically significant association was found (OR: 1.08, 95\% CI: $0.70-1.67, \mathrm{P}=0.71$ ). As for males, Dahlstrom et al reported a high prevalence of oral HPV infection in men who had oral sex experience, though no significant association between oral sex and HPV infection was found. With regard to smoking habit, we found that smoking was significantly associated with oral HPV infection (OR: 2.13, 95\% CI: 1.32 - 3.43, P=0.0024) (Fig. 2B). In addition, that association was significant in females (OR: 2.19, $95 \% \mathrm{CI}: 1.26-3.82, \mathrm{P}=0.0058)[12,13,23]$, indicating a strong relationship between females and HPV prevalence. In their previous study, Dahlstrom et al found a statistically significant association between smoking and oral HPV infection in males [13]. Together, these results suggest that oral sex experience and smoking are related to oral HPV infection, while it is important to note that smoking is strongly associated with oral HPV infection in females. Publication bias was evaluated by use of a funnel plot and Begg's rank correlation test, with no significant bias detected for oral sex experience or smoking $(\mathrm{P}>0.05)$.

\section{Discussion}

Keimer et al reported oral HPV infection rates (overall HPV infection rate: $4.5 \%$ and HPV16 infection rate: $1.3 \%$ ) in healthy individuals in a systematic review [42]. Our results showed higher HPV infection rates than those reported by Keimer et al. This is explained by the involvement of male same-sex partners. Keimer et al reported that prevalence rates for overall HPV were nearly the same in males and females $(4.6 \%$ vs. $4.4 \%)$ [42]. In the present study, the overall prevalence rate for HPV was lower in females $(2.9 \%)$ than in males $(4.7 \%)$, indicating the possibility of a recent slight decrease in rate of HPV infection in females. As for HPV16, our results showed nearly the same infection rate $(1.0 \%)$ as in that previous study $(1.3 \%)$. We speculated that HPV16 is a common high-risk type of HPV found not only in the cervix but also 


\begin{tabular}{|c|c|c|c|c|c|c|c|}
\hline A & Gender* & $\begin{array}{l}\text { No. of HPV po } \\
\text { / Total No. } \%\end{array}$ & itive cases & Odds ratio & $95 \%-\mathrm{Cl}$ & Weight (\%) & Forest plot \\
\hline 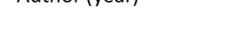 & ofrice & Oral sex $(+)$ & Oral sex (-) & & & & \\
\hline Antonsson et al (2014) & $M / F$ & $6 / 224(2.7 \%)$ & $1 / 51(2.0 \%)$ & 1.38 & {$[0.16,11.7]$} & 1.31 & \\
\hline Cook et al (2014) & $\mathrm{F}$ & $17 / 778(2.2 \%)$ & $2 / 230(0.87 \%)$ & 2.55 & {$[0.58,11.1]$} & 2.50 & \\
\hline Dahlstrom et al (2014) & M & $15 / 174(8.6 \%)$ & $1 / 48(2.1 \%)$ & 4.43 & {$[0.57,34.5]$} & 1.19 & \\
\hline Hang et al (2014) & $M / F$ & $3 / 111(2.7 \%)$ & $33 / 2705(1.2 \%)$ & 2.25 & {$[0.68,7.45]$} & 2.10 & \\
\hline Meyer et al (2014) & $\mathrm{F}$ & $5 / 77(6.5 \%)$ & $2 / 52(3.8 \%)$ & 1.74 & {$[0.32,9.30]$} & 1.85 & \\
\hline Vidotti et al (2014) & $\mathrm{F}$ & $5 / 32(15.6 \%)$ & $20 / 73(27.4 \%)$ & 0.49 & {$[0.17,1.45]$} & 8.52 & -11 \\
\hline Lang et al (2013) & $\mathrm{F}$ & $35 / 1801$ (19.4\%) & 20/1125 (17.8\%) & 1.09 & {$[0.63,1.91]$} & 20.0 & \\
\hline Gillison et al (2012) & $M / F$ & $300 / 3452(8.7 \%)$ & $59 / 1473(4.0 \%)$ & 1.10 & {$[1.71,3.04]$} & 62.5 & - \\
\hline Overall & $M / F$ & $386 / 6649(5.8 \%)$ & $138 / 5757(2.4 \%)$ & 1.90 & {$[1.51,2.39]$} & 100.0 & $\Leftrightarrow$ \\
\hline
\end{tabular}



Figure 2. Meta-analysis of the association between oral HPV infection and sexual behavior, smoking and drinking. (A) Forest plot of overall oral HPV infection and oral sex. Meta-analysis using a fixed effects model demonstrated that oral sex was significantly correlated with oral HPV infection (P < 0.0001). *Gender: M: male; F: female. (B) Forest plot of overall HPV infection and smoking. Meta-analysis using a random effects model demonstrated that smoking status was significantly correlated with oral HPV infection $(P=0.002)$. *Gender: M: male; F: female.

the oral cavity.

The results of this analysis demonstrated that oral environmental changes due to sexual behaviors and smoking strongly influenced HPV infection. Oral HPV infection is likely to be transmitted to partners through sexual behaviors because of the absence of subjective symptoms. In addition, biological reasons why smoking is involved in HPV infection include the induction of inflammation and suppression of immune mechanisms in the oral mucosa, caused by chemical substances contained in tobacco [22]. Periodontitis and gingivitis are also potential risk factors for HPV infection [43-45]. Poor oral hygiene may increase the risk of HPV infection. A comparison of HPV infection between denture users and nonusers demonstrated a higher HPV infection rate in the former, demonstrating that oral mucosal injuries caused by mechanical stimulation of dentures and poor oral hygiene due to unclean dentures were involved in HPV infection [46]. In addition, the oral HPV infection rate is higher in women with HPV-infected cervices, suggesting that HPV infection in the cervix is another risk factor for oral HPV infection [47].

Gillison et al show bimodal peaks of HPV infection at the ages of about 30 and 55 and about 25 and 55 in males and females, respectively, suggesting that increased sexual activities and decreased oral immune functions due to aging might have raised infection rates [31]. In Japan, the decreasing average age at starting sexual activities may have increased the HPV infection rate in young people [48, 49]. The most common high-risk type of HPV infection seen in the oral cavity and cervix of sexually active young people is HPV16 [9, 12, $13,27,47]$. Furthermore, HPV42 is a common low-risk HPV type seen in those locations in young females [9, 27], while HPV18 is commonly found in the cervix but not the oral cavity in young subjects $[9,12,13,27]$. Most HPV types commonly detected in the cervix are also found in the oral cavity, suggesting that concomitant HPV infection in those locations is common in young females $[27,50]$. In addition, detection of the same HPV type in both oral and cervical samples was reported to be much higher in HIV-positive as compared to HIV-negative women [51], indicating that sexual activity and suppressed immune function may induce concomitant infection with the same HPV type in the oral cavity and cervix in females. In a study of elderly subjects, Castle et al found increased cervical HPV prevalence and persistence of HPV infection in females older than 65 years despite their low level of sexual activity [52]. In another study, persistent cervical HPV16 infection was associated with a low lymphoproliferative response in older women, indicating that the increased rate of HPV infection seen in older individuals may be associated with suppression 
of host immunologic responses [53]. As for oral HPV infection in older individuals, not only impairment of systemic host immune response but also that of local environments, caused by such factors as denture use and poor oral hygiene due to lack of self-care, may induce increased risk of oral HPV infection.

Smoking significantly increases the risk of oral HPV infection in both males and females [12, 13, 22, 23]. In our study, we found a significant relationship between smoking and oral HPV infection in females. In addition, Gillison et al reported that female smokers had a significantly higher prevalence of HPV infection as compared to male smokers (10 - 20 cigarettes/day, $4.23 \%$ vs. $1.29 \%$; > 20 cigarettes/day, $5.92 \%$ vs. $1.58 \%$ ) [31], supporting the notion that smoking is significantly associated with oral HPV infection in females. However, it remains unclear why female smokers are more susceptible to oral HPV, though smoking-inhibited humoral immunity may be a factor.

HPV is thought to be sexually transmitted to the oral cavity via oral sex and open mouth kissing [54]. As for oral sex, several studies have found that oral sex experience and number of oral sex partners are significant risk factors for oral HPV infection [11-14, 33]. However, it remains controversial whether oral sex is an independent risk factor for oral HPV infection among males and females. Oral sex has been reported to increase the risk of HPV infection among young men (18 - 24 years) and young women (mean age 21.9 years) [12, 13, 54]. On the other hand, other studies did not find a significant association between that and HPV infection in men or women [20, $22,23]$. These conflicting results may be attributed to the characteristics of the study participants (i.e., sexual activity, sexual behavior, and genital HPV infection status of sexual partner). Furthermore, oral to oral contact (i.e., open mouth kissing) is also an important route of HPV transmission, and a significant risk factor for oral HPV infection in young men and women $[33,54]$. Additional studies that focus on the oral/genital HPV status of healthy couples may help to clarify the correlation between oral HPV infection and sexual behavior, such as oral sex and open mouth kissing.

Four prospective cohort studies to follow-up individual subjects provided new findings regarding the duration of persistent HPV infection [15, 22, 28, 32]. Rautava et al investigated 324 women for 6 years, demonstrating the highest HPV16 infection rate during follow-up periods and a mean HPV16 infection period of 18.6 months [32]. Kero et al investigated 131 fathers for 7 years, demonstrating a mean HPV16 infection period of 21.7 months, the longest duration of high-risk type HPV infection [15]. In addition, smoking was previously demonstrated to increase the duration of infection with highrisk type HPV (HPV16, 18, 31, 33, 35, 39, 45, 52, 58, and 59) [15]. HPV infection is thought to induce HPV-specific immunity by aiding the clearance of subsequent HPV organisms [55]. Oral HPV-infection was shown to be related to increased concentrations of salivary $\operatorname{IgG}$ and lysozyme, indicating that humoral immunity plays a role in clearance of HPV from the oral cavity [56]. However, smoking can inhibit immune response in the oral cavity because of its oxidant components, such as carbon monoxide, nicotine, and other chemical compounds [57]. Thus, local immunosuppressive effects of smoking may affect susceptibility to HPV infection and increase the duration of virus infection in the oral cavity. In addition, smoking reduces the level of serum anti-HPV antibodies in cervical HPV-positive females, suggesting that it inhibits seroconversion in response to HPV infection [58]. Kreimer et al surveyed oral HPV infection in 1,626 men for 4 years, demonstrating that the mean durations of HPV and HPV16 type were 6.9 and 7.3 months, respectively, and that most HPV infections disappeared within 1 year [22]. Furthermore, HPV16 infection is more persistent in the elderly than in young people [45]. Thus, although most HPV infections disappear within 1 year, HPV16 infection continues from 6 months to several years. Smoking and aging are risk factors for prolonged high-risk HPV type infections. Persistent high-risk HPV type infections through smoking may be involved in the development of HPV-related oral cancer.

The prevalence of oral cancer in Europe and the United States shows a downward trend due to decreasing smoking rates, but remains high in India and its neighboring countries $[59,60]$. The oral cavity is anatomically susceptible to various physical, chemical, and biohazard factors. Risk factors for oral cancer include smoking, drinking, oral hygiene, periodontitis, chronic mechanical stimulus, and viral infection [61]. Thus, many risk factors, including HPV, may act synergistically in the oral cavity, unlike in the cervix, causing oral cancer. HPV is markedly different from other DNA viruses in that it cannot be cultured in vitro or eliminated by the immune system. HPV infects and remains in the basal cells, but is released outside the body upon the differentiation of the infected cells into keratinocytes, and, therefore, does not enter the blood, thereby evading immune surveillance. When the mucous membrane is injured, HPV is incorporated as a nuclear episome into the basal cells and remains as transient infection. Meanwhile, HPV replicates within the cell nucleus, and, if the viral genome is integrated into the host genome, it causes persistent infection for several years. Subsequently, atypical cells develop and increase in the epithelium to be recognized as a precancerous lesion, which becomes malignant and progresses to squamous cell carcinoma. Thus, it takes several to more than 10 years for HPV to infect cells and cause carcinogenesis. Ndiaye et al reported that $32 \%$ of all head and neck cancer patients were positive for HPV, of whom 82\% were positive for HPV16 [62]. In addition, $24 \%, 14.9 \%$, and $5.9 \%$ of all oral cancer patients were positive for HPV, HPV16, and HPV18, respectively [62]. We previously determined the positive rates of oral HPV16 infection $(36 \%$ in the normal mucosa, $61 \%$ in epithelial dysplasia, and $35 \%$ in squamous cell carcinoma), showing that the HPV16-positive rate was the highest in precancerous lesions. HPV 16 was positive in $82 \%$ of epithelial dysplasia cases that finally progressed to cancer [5]. These findings suggest that HPV16 plays an important role in promoting malignant transformation during progression from epithelial dysplasia to squamous cell carcinoma.

Following integration of HPV DNA into the genome of infected cells, the expressions of E6 and E7 proteins suppressed by $\mathrm{E} 2$ protein are reactivated, thus inducing the overexpression of oncogene products by E6 and E7 [63]. Thus, HPV DNA integration into host genomes can be examined by investigating E6 and E7 expression. Specifically, those protein expressions as well as detection of HPV DNA are necessary to demonstrate 
that HPV is involved in carcinogenesis. Currently, RT-PCR is widely employed to analyze E6 and E7 mRNA expressions. Recent studies demonstrated that the positive rates of E6 and E7 mRNAs in oral squamous cell carcinoma were 0-9.4\% [6470]. The positive rates of E6 and E7 mRNAs in Japanese were $10 \%$ in oral cancer, $52.2 \%$ in oropharyngeal cancer (tonsil cancer), and $25 \%$ in laryngeal cancer, demonstrating the highest prevalence in oropharyngeal cancer [71]. In addition, the copy number of the HPV16 genome was high in oropharyngeal cancer, demonstrating that the oropharynx is a common site for HPV16 infection compared with other head and neck region [71]. Previous meta-analysis demonstrated that the positive rates of E6 and E7 mRNAs were higher in oropharyngeal cancer than in oral and laryngeal cancers, strongly suggesting that $\mathrm{HPV}$-related cancer genes play an important role in malignant transformation to oropharyngeal cancer [62]. Thus, the HPV infection rates and oncogene expressions vary among different sites (i.e., oral, oropharyngeal and laryngeal site), showing the interesting biological characteristics of HPV-related cancers. It has not been fully elucidated why the oropharyngeal region is more susceptible to HPV infection than the oral cavity. Importantly, there are histological differences between the oral cavity and tonsillar region [72]. For example, lymphoid tissues are abundant in the palatine tonsils of the oropharynx and base of the tongue. Furthermore, squamous epithelium lines the surface of the oral cavity, whereas reticulated-epithelium lining tonsillar crypts is a characteristic of the tonsillar region. The specific anatomic structure of the tonsillar region may be sensitive to HPV infection because the viral organisms may become trapped in tonsillar crypts and then infect basal keratinocytes by invading through the epithelium.

\section{Conclusions}

We found that sexual behavior and smoking are related to oral HPV infection in healthy individuals. Importantly, current smoking was shown to be a significant risk factor for oral HPV infection in females. A clear understanding that smoking, oral hygiene, and sexual behaviors are risk factors for oral HPV infection may lower oral HPV infection rates, while elucidation of the related molecular biology will reduce the occurrence of HPV-related cancers.

\section{Competing Interests}

The authors declare that they have no competing interests.

\section{Grant Support}

None.

\section{Financial Disclosure}

None.

\section{Abbreviations}

HPV: human papillomavirus; OR: odds ratio; CI: confidence interval

\section{References}

1. Doorbar J, Quint W, Banks L, Bravo IG, Stoler M, Broker TR, Stanley MA. The biology and life-cycle of human papillomaviruses. Vaccine. 2012;30(Suppl 5):F55-70.

2. de Villiers EM, Fauquet C, Broker TR, Bernard HU, zur Hausen H. Classification of papillomaviruses. Virology. 2004;324(1):17-27.

3. Durst M, Gissmann L, Ikenberg H, zur Hausen H. A papillomavirus DNA from a cervical carcinoma and its prevalence in cancer biopsy samples from different geographic regions. Proc Natl Acad Sci U S A. 1983;80(12):38123815.

4. zur Hausen H. Papillomaviruses and cancer: from basic studies to clinical application. Nat Rev Cancer. 2002;2(5):342-350.

5. Sugiyama M, Bhawal UK, Dohmen T, Ono S, Miyauchi $\mathrm{M}$, Ishikawa $\mathrm{T}$. Detection of human papillomavirus-16 and HPV-18 DNA in normal, dysplastic, and malignant oral epithelium. Oral Surg Oral Med Oral Pathol Oral Radiol Endod. 2003;95(5):594-600.

6. Sugiyama M, Bhawal UK, Kawamura M, Ishioka Y, Shigeishi H, Higashikawa K, Kamata N. Human papillomavirus-16 in oral squamous cell carcinoma: clinical correlates and 5-year survival. Br J Oral Maxillofac Surg. 2007;45(2):116-122.

7. Beachler DC, Sugar EA, Margolick JB, Weber KM, Strickler HD, Wiley DJ, Cranston RD, et al. Risk factors for acquisition and clearance of oral human papillomavirus infection among HIV-infected and HIV-uninfected adults. Am J Epidemiol. 2015;181(1):40-53.

8. Dalla Torre D, Burtscher D, Edlinger M, Solder E, Widschwendter A, Rasse M, Puelacher W. Comparison of the prevalence of human papilloma virus infection in histopathologically confirmed premalignant oral lesions and healthy oral mucosa by brush smear detection. Oral Surg Oral Med Oral Pathol Oral Radiol. 2015;119(3):333-339.

9. Grun N, Ahrlund-Richter A, Franzen J, Mirzaie L, Marions L, Ramqvist T, Dalianis T. Oral human papillomavirus (HPV) prevalence in youth and cervical HPV prevalence in women attending a youth clinic in Sweden, a follow up-study 2013-2014 after gradual introduction of public HPV vaccination. Infect Dis (Lond). 2015;47(1):57-61.

10. King EM, Gilson R, Beddows S, Soldan K, Panwar K, Young C, Jit M, et al. Oral human papillomavirus (HPV) infection in men who have sex with men: prevalence and lack of anogenital concordance. Sex Transm Infect. 2015;91(4):284-286.

11. Antonsson A, Cornford M, Perry S, Davis M, Dunne MP, Whiteman DC. Prevalence and risk factors for oral HPV infection in young Australians. PLoS One. 2014;9(3):e91761. 
12. Cook RL, Thompson EL, Kelso NE, Friary J, Hosford J, Barkley P, Dodd VJ, et al. Sexual behaviors and other risk factors for oral human papillomavirus infections in young women. Sex Transm Dis. 2014;41(8):486-492.

13. Dahlstrom KR, Burchell AN, Ramanakumar AV, Rodrigues A, Tellier PP, Hanley J, Coutlee F, et al. Sexual transmission of oral human papillomavirus infection among men. Cancer Epidemiol Biomarkers Prev. 2014;23(12):2959-2964.

14. Hang D, Liu F, Liu M, He Z, Sun M, Liu Y, Li J, et al. Oral human papillomavirus infection and its risk factors among 5,410 healthy adults in China, 2009-2011. Cancer Epidemiol Biomarkers Prev. 2014;23(10):2101-2110.

15. Kero K, Rautava J, Syrjanen K, Willberg J, Grenman S, Syrjanen S. Smoking increases oral HPV persistence among men: 7-year follow-up study. Eur J Clin Microbiol Infect Dis. 2014;33(1):123-133.

16. Lima MD, Braz-Silva PH, Pereira SM, Riera C, Coelho AC, Gallottini M. Oral and cervical HPV infection in HIV-positive and HIV-negative women attending a sexual health clinic in Sao Paulo, Brazil. Int J Gynaecol Obstet. 2014;126(1):33-36.

17. Mbulawa ZZ, Johnson LF, Marais DJ, Coetzee D, Williamson AL. Risk factors for oral human papillomavirus in heterosexual couples in an African setting. J Infect. 2014;68(2):185-189.

18. Meyer MF, Huebbers CU, Siefer OG, Vent J, Engbert I, Eslick GD, Valter M, et al. Prevalence and risk factors for oral human papillomavirus infection in 129 women screened for cervical HPV infection. Oral Oncol. 2014;50(1):27-31.

19. Tatar TZ, Kis A, Szabo E, Czompa L, Boda R, Tar I, Szarka K. Prevalence of human papillomaviruses in the healthy oral mucosa of women with high-grade squamous intra-epithelial lesion and of their partners as compared to healthy controls. J Oral Pathol Med. 2015;44(9):722-727.

20. Vidotti LR, Vidal FC, Monteiro SC, Nunes JD, Salgado JV, Brito LM, Lopes FF. Association between oral DNA-HPV and genital DNA-HPV. J Oral Pathol Med. 2014;43(4):289-292.

21. Cavenaghi VB, Ghosn EJ, Cruz N, Rossi LM, da Silva L, Costa HO, Villa LL. Determination of HPV prevalence in oral/oropharyngeal mucosa samples in a rural district of Sao Paulo. Braz J Otorhinolaryngol. 2013;79(5):599-602.

22. Kreimer AR, Pierce Campbell CM, Lin HY, Fulp W, Papenfuss MR, Abrahamsen M, Hildesheim A, et al. Incidence and clearance of oral human papillomavirus infection in men: the HIM cohort study. Lancet. 2013;382(9895):877887.

23. Lang Kuhs KA, Gonzalez P, Struijk L, Castro F, Hildesheim A, van Doorn LJ, Rodriguez AC, et al. Prevalence of and risk factors for oral human papillomavirus among young women in Costa Rica. J Infect Dis. 2013;208(10):1643-1652.

24. Mooij SH, Boot HJ, Speksnijder AG, Stolte IG, Meijer CJ, Snijders PJ, Verhagen DW, et al. Oral human papillomavirus infection in HIV-negative and HIV-infected MSM. AIDS. 2013;27(13):2117-2128.

25. Seifi S, Asvadi Kermani I, Dolatkhah R, Asvadi Kermani
A, Sakhinia E, Asgarzadeh M, Dastgiri S, et al. Prevalence of oral human papilloma virus in healthy individuals in East azerbaijan province of iran. Iran J Public Health. 2013;42(1):79-85.

26. Beachler DC, Weber KM, Margolick JB, Strickler HD, Cranston RD, Burk RD, Wiley DJ, et al. Risk factors for oral HPV infection among a high prevalence population of HIV-positive and at-risk HIV-negative adults. Cancer Epidemiol Biomarkers Prev. 2012;21(1):122-133.

27. Du J, Nordfors C, Ahrlund-Richter A, Sobkowiak M, Romanitan M, Nasman A, Andersson S, et al. Prevalence of oral human papillomavirus infection among youth, Sweden. Emerg Infect Dis. 2012;18(9):1468-1471.

28. Edelstein ZR, Schwartz SM, Hawes S, Hughes JP, Feng Q, Stern ME, O'Reilly S, et al. Rates and determinants of oral human papillomavirus infection in young men. Sex Transm Dis. 2012;39(11):860-867.

29. Flake C, Arafa J, Hall A, Ence E, Howard K, Kingsley K. Screening and detection of human papillomavirus (HPV) high-risk strains HPV16 and HPV18 in saliva samples from subjects under 18 years old in Nevada: a pilot study. BMC Oral Health. 2012;12:43.

30. Gichki AS, Buajeeb W, Doungudomdacha S, Khovidhunkit SO. Detection of human papillomavirus in normal oral cavity in a group of Pakistani subjects using real-time PCR. Asian Pac J Cancer Prev. 2012;13(5):2299-2304.

31. Gillison ML, Broutian T, Pickard RK, Tong ZY, Xiao W, Kahle L, Graubard BI, et al. Prevalence of oral HPV infection in the United States, 2009-2010. JAMA. 2012;307(7):693-703.

32. Rautava J, Willberg J, Louvanto K, Wideman L, Syrjanen K, Grenman S, Syrjanen S. Prevalence, genotype distribution and persistence of human papillomavirus in oral mucosa of women: a six-year follow-up study. PLoS One. 2012;7(8):e42171.

33. Pickard RK, Xiao W, Broutian TR, He X, Gillison ML. The prevalence and incidence of oral human papillomavirus infection among young men and women, aged 18-30 years. Sex Transm Dis. 2012;39(7):559-566.

34. Read TR, Hocking JS, Vodstrcil LA, Tabrizi SN, McCullough MJ, Grulich AE, Garland SM, et al. Oral human papillomavirus in men having sex with men: risk-factors and sampling. PLoS One. 2012;7(11):e49324.

35. Tristao W, Ribeiro RM, Oliveira CA, Betiol JC, Bettini Jde S. Epidemiological study of HPV in oral mucosa through PCR. Braz J Otorhinolaryngol. 2012;78(4):66-70.

36. Kanda Y. Investigation of the freely available easy-touse software 'EZR' for medical statistics. Bone Marrow Transplant. 2013;48(3):452-458.

37. Qu W, Jiang G, Cruz Y, Chang CJ, Ho GY, Klein RS, Burk RD. PCR detection of human papillomavirus: comparison between MY09/MY11 and GP5+/GP6+ primer systems. J Clin Microbiol. 1997;35(6):1304-1310.

38. Giovannelli L, Lama A, Capra G, Giordano V, Arico P, Ammatuna P. Detection of human papillomavirus DNA in cervical samples: analysis of the new PGMY-PCR compared to the hybrid capture II and MY-PCR assays and a two-step nested PCR assay. J Clin Microbiol. 2004;42(8):3861-3864. 
39. Dunn ST, Allen RA, Wang S, Walker J, Schiffman M. DNA extraction: an understudied and important aspect of HPV genotyping using PCR-based methods. J Virol Methods. 2007;143(1):45-54.

40. Bouvard V, Baan R, Straif K, Grosse Y, Secretan B, El Ghissassi F, Benbrahim-Tallaa L, et al. A review of human carcinogens - Part B: biological agents. Lancet Oncol. 2009;10(4):321-322.

41. Biological agents. Volume 100 B. A review of human carcinogens. IARC Monogr Eval Carcinog Risks Hum. 2012;100(Pt B):1-441.

42. Kreimer AR, Bhatia RK, Messeguer AL, Gonzalez P, Herrero R, Giuliano AR. Oral human papillomavirus in healthy individuals: a systematic review of the literature. Sex Transm Dis. 2010;37(6):386-391.

43. Hormia M, Willberg J, Ruokonen H, Syrjanen S. Marginal periodontium as a potential reservoir of human papillomavirus in oral mucosa. J Periodontol. 2005;76(3):358363.

44. Engels EA, Biggar RJ, Hall HI, Cross H, Crutchfield A, Finch JL, Grigg R, et al. Cancer risk in people infected with human immunodeficiency virus in the United States. Int J Cancer. 2008;123(1):187-194.

45. Tezal M, Sullivan Nasca M, Stoler DL, Melendy T, Hyland A, Smaldino PJ, Rigual NR, et al. Chronic periodontitishuman papillomavirus synergy in base of tongue cancers. Arch Otolaryngol Head Neck Surg. 2009;135(4):391396.

46. Nishimura Y, Maeda H, Hattori M, Azumaya F, Muramatsu I, Kameyama Y, Tanaka Y, et al. [Human papillomavirus infection in the oral cavity of denture wearers]. Nihon Hotetsu Shika Gakkai Zasshi. 2004;48(5):713-722.

47. Adamopoulou M, Vairaktaris E, Nkenke E, Avgoustidis D, Karakitsos P, Sioulas V, Nisyrios T, et al. Prevalence of human papillomavirus in saliva and cervix of sexually active women. Gynecol Oncol. 2013;129(2):395-400.

48. Ghotbi N, Anai A. Assessment of the knowledge and attitude of female students towards cervical cancer prevention at an international university in Japan. Asian Pac J Cancer Prev. 2012;13(3):897-900.

49. Inoue M, Sakaguchi J, Sasagawa T, Tango M. The evaluation of human papillomavirus DNA testing in primary screening for cervical lesions in a large Japanese population. Int J Gynecol Cancer. 2006;16(3):1007-1013.

50. Giraldo P, Goncalves AK, Pereira SA, Barros-Mazon $\mathrm{S}$, Gondo ML, Witkin SS. Human papillomavirus in the oral mucosa of women with genital human papillomavirus lesions. Eur J Obstet Gynecol Reprod Biol. 2006;126(1):104-106.

51. Termine N, Giovannelli L, Matranga D, Caleca MP, Bellavia C, Perino A, Campisi G. Oral human papillomavirus infection in women with cervical HPV infection: new data from an Italian cohort and a metanalysis of the literature. Oral Oncol. 2011;47(4):244-250.

52. Castle PE, Schiffman M, Herrero R, Hildesheim A, Rodriguez $\mathrm{AC}$, Bratti $\mathrm{MC}$, Sherman $\mathrm{ME}$, et al. A prospective study of age trends in cervical human papillomavirus acquisition and persistence in Guanacaste, Costa Rica. J Infect Dis. 2005;191(11):1808-1816.
53. Garcia-Pineres AJ, Hildesheim A, Herrero R, Trivett M, Williams M, Atmetlla I, Ramirez M, et al. Persistent human papillomavirus infection is associated with a generalized decrease in immune responsiveness in older women. Cancer Res. 2006;66(22):11070-11076.

54. D'Souza G, Agrawal Y, Halpern J, Bodison S, Gillison ML. Oral sexual behaviors associated with prevalent oral human papillomavirus infection. J Infect Dis. 2009;199(9):1263-1269.

55. Stanley MA. Epithelial cell responses to infection with human papillomavirus. Clin Microbiol Rev. 2012;25(2):215222.

56. Haukioja A, Asunta M, Soderling E, Syrjanen S. Persistent oral human papillomavirus infection is associated with smoking and elevated salivary immunoglobulin $\mathrm{G}$ concentration. J Clin Virol. 2014;61(1):101-106.

57. Stampfli MR, Anderson GP. How cigarette smoke skews immune responses to promote infection, lung disease and cancer. Nat Rev Immunol. 2009;9(5):377-384.

58. Wiley DJ, Wiesmeier E, Masongsong E, Gylys KH, Koutsky LA, Ferris DG, Barr E, et al. Smokers at higher risk for undetected antibody for oncogenic human papillomavirus type 16 infection. Cancer Epidemiol Biomarkers Prev. 2006;15(5):915-920.

59. Giuliano AR, Nyitray AG, Kreimer AR, Pierce Campbell CM, Goodman MT, Sudenga SL, Monsonego J, et al. EUROGIN 2014 roadmap: differences in human papillomavirus infection natural history, transmission and human papillomavirus-related cancer incidence by gender and anatomic site of infection. Int $\mathrm{J}$ Cancer. 2015;136(12):2752-2760.

60. Warnakulasuriya S. Global epidemiology of oral and oropharyngeal cancer. Oral Oncol. 2009;45(4-5):309-316.

61. Sturgis EM, Cinciripini PM. Trends in head and neck cancer incidence in relation to smoking prevalence: an emerging epidemic of human papillomavirus-associated cancers? Cancer. 2007;110(7):1429-1435.

62. Ndiaye C, Mena M, Alemany L, Arbyn M, Castellsague X, Laporte L, Bosch FX, et al. HPV DNA, E6/E7 mRNA, and p16INK4a detection in head and neck cancers: a systematic review and meta-analysis. Lancet Oncol. 2014;15(12):1319-1331.

63. Arias-Pulido H, Peyton CL, Joste NE, Vargas H, Wheeler $\mathrm{CM}$. Human papillomavirus type 16 integration in cervical carcinoma in situ and in invasive cervical cancer. $\mathrm{J}$ Clin Microbiol. 2006;44(5):1755-1762.

64. Jordan RC, Lingen MW, Perez-Ordonez B, He X, Pickard $\mathrm{R}$, Koluder M, Jiang B, et al. Validation of methods for oropharyngeal cancer HPV status determination in US cooperative group trials. Am J Surg Pathol. 2012;36(7):945954.

65. Braakhuis BJ, Snijders PJ, Keune WJ, Meijer CJ, RuijterSchippers HJ, Leemans CR, Brakenhoff RH. Genetic patterns in head and neck cancers that contain or lack transcriptionally active human papillomavirus. J Natl Cancer Inst. 2004;96(13):998-1006.

66. Tsimplaki E, Argyri E, Xesfyngi D, Daskalopoulou D, Stravopodis DJ, Panotopoulou E. Prevalence and expression of human papillomavirus in 53 patients with 
oral tongue squamous cell carcinoma. Anticancer Res. 2014;34(2):1021-1025.

67. Lewis JS, Jr., Ukpo OC, Ma XJ, Flanagan JJ, Luo Y, Thorstad WL, Chernock RD. Transcriptionally-active high-risk human papillomavirus is rare in oral cavity and laryngeal/hypopharyngeal squamous cell carcinomas - a tissue microarray study utilizing E6/E7 mRNA in situ hybridization. Histopathology. 2012;60(6):982-991.

68. Poling JS, Ma XJ, Bui S, Luo Y, Li R, Koch WM, Westra WH. Human papillomavirus (HPV) status of non-tobacco related squamous cell carcinomas of the lateral tongue. Oral Oncol. 2014;50(4):306-310.

69. Lingen MW, Xiao W, Schmitt A, Jiang B, Pickard R, Kreinbrink P, Perez-Ordonez B, et al. Low etiologic fraction for high-risk human papillomavirus in oral cavity squamous cell carcinomas. Oral Oncol. 2013;49(1):1-8.
70. Bishop JA, Ma XJ, Wang H, Luo Y, Illei PB, Begum $\mathrm{S}$, Taube JM, et al. Detection of transcriptionally active high-risk HPV in patients with head and neck squamous cell carcinoma as visualized by a novel E6/E7 mRNA in situ hybridization method. Am J Surg Pathol. 2012;36(12):1874-1882.

71. Deng Z, Hasegawa M, Kiyuna A, Matayoshi S, Uehara T, Agena S, Yamashita Y, et al. Viral load, physical status, and E6/E7 mRNA expression of human papillomavirus in head and neck squamous cell carcinoma. Head Neck. 2013;35(6):800-808.

72. Klussmann JP, Weissenborn SJ, Wieland U, Dries V, Kolligs J, Jungehuelsing M, Eckel HE, et al. Prevalence, distribution, and viral load of human papillomavirus 16 DNA in tonsillar carcinomas. Cancer. 2001;92(11):28752884. 